\title{
Urbanization-induced Land Use and Cover Changes in Xuzhou, Jiangsu Province since the Mid-1990s
}

\author{
Hui Dai ${ }^{1}$, Xuezhen Zhang ${ }^{2,3}{ }^{*}$ and Zhaoling $\mathrm{Hu}^{1}$ \\ ${ }^{1}$ Jiangsu Normal University, Xuzhou 221116, China \\ ${ }^{2}$ Key Laboratory of Land Surface Pattern and Simulation, Institute of Geographical Sciences and Natural \\ Resources Research, Chinese Academy of Sciences, Beijing 100101, China \\ ${ }^{3}$ University of Chinese Academy of Sciences, Beijing 100049, China \\ Email: xzzhang@igsnrr.ac.cn
}

\begin{abstract}
The characteristics of urban expansion and land use change in Xuzhou, Jiangsu Province were studied using Landsat images from 1994, 2005 and 2014. First, we used the maximum likelihood method to perform a supervised classification to retrieve land use/cover categories. With the confusion matrix approach, the total accuracy of the classification was estimated to be $90.38 \%$, $89.81 \%$ and $89.57 \%$, respectively, for 1994, 2005, and 2014. Second, by comparing land use patterns with each other for the three time slices, urban expansion and land use changes were revealed. The results show that urban area increased from $135.48 \mathrm{~km}^{2}$ in 1994 to $323.28 \mathrm{~km}^{2}$ in 2005 and to 456.33 $\mathrm{km}^{2}$ in 2014. The newly developed urban areas mainly extended to the southwest from 1994 to 2005 and to the east and southeast from 2005 to 2014. The expansion of urban area mostly came at the cost of a decrease in arable land. The net conversions from arable land to urban area reached as high as $298.04 \mathrm{~km}^{2}$ during the period from 1994 to 2014. At the decadal scale, the urban expansion appears likely to precede economic growth. The implication is that urban expansion provided good conditions for economic growth rather than being driven by economic growth.
\end{abstract}

Keywords: Urban expansion, land use and cover changes, remote sensing images, Xuzhou.

\section{Introduction}

Along with the great economic achievements in China since the 1980s, tremendous urbanization occurred across the country. One of the distinguishing features of urbanization is the expansion of the urban area, i.e., a conversion from field landscape to metropolis landscape (e.g., Bai et al., 2012; Liu et al., 2014; Deng et al., 2015). Such conversion is an important indicator of human modification of the land surface. According to ground measurements, between 1981 and 2010, China's urban area increased 4.39-fold, from $7,438 \mathrm{~km}^{2}$ to $40,058 \mathrm{~km}^{2}$ (Ministry of Housing and Urban-Rural Development PRC, 2011). Along with the urbanization-induced land use/cover changes (LUCC) from vegetation-covered area to built-up area, related environmental issues, such as urban heat islands, flooding, air pollution, etc., occur (e.g., Liu et al., 2015; Zhang et al., 2016). Depiction of the spatial pattern of the urbanization-induced LUCC would, therefore, be an essential task for resolving these environmental issues and improving landscape planning; thus, it is a hot topic in the community of understanding human-environmental interactions.

Remote sensing, as an effective technology for observing land surface, has been used extensively to detect urbanization-induced LUCC (e.g., Xiao et al., 2006; Du et al., 2010; Sertel et al., 2012). For instance, using the nighttime stable light (NSL) images from the Operational Line-scan System (OLS) of the Defense Meteorological Satellite Program (DMSP), it was estimated that urban and built-up areas across China increased from $1.22 \times 10^{4} \mathrm{~km}^{2}$ in 1992 to $7.29 \times 10^{4} \mathrm{~km}^{2}$ in 2015 , increasing in size nearly five-fold and with an average annual growth rate of $8.10 \%$. This rate is almost 2.5 times as rapid as the global average (Xu et al., 2016). Based on the Landsat Thematic Mapper (TM) and Enhanced Thematic Mapper Plus (ETM+) images combined with China-Brazil Earth Resources Satellite (CBERS-1) images, it was reported that the urban area increased by $1.26,0.49,1.7$ and $2.1 \times 10^{4} \mathrm{~km}^{2}$, respectively, in the four segments of five-year periods, i.e., 1991-1995, 1996-2000, 2001-2005, and 2006-2010 (e.g., Liu et al, 
2003; Liu et al., 2010; Liu et al., 2014). Generally, the urban lands' expansion rate in the 2000s was 2.15 times that in the 1990s (Kuang et al., 2016), and the greatest areas of urbanization occurred from the northeastern provinces in the 1990s to the southeast coast of China in Jiangsu, Guangdong, Shandong, and Zhejiang in the 2010s (e.g., Wang et al., 2012). To depict geographic differences of temporal evolution of urbanization-induced LUCC across the China, Wen et al. (2016) reconstructed the urban area changes from 1973 to 2013 for 60 representative cities using Landsat Multi Spectral Scanner (MSS) images, Landsat TM and ETM images, combining the CBERS-1 images, Chinese Huanjing (HJ-1) images, and Landsat Data Continuity Mission (LDCM) images. Then, the temporal evolution of the urban area was classified into four models: 1) peaked in approximately 2004 and then decelerated; 2) peaked in approximately 2010 and then decelerated; 3) sustained acceleration; and 4) continued deceleration.

The aforementioned studies well illustrated the general characteristics of urbanization-induced LUCC at the national level. More studies on individual cities would be needed to clearly depict spatial patterns of urban expansion in order to understand urban expansion dynamics, as the expansions have large variability among the cities. For instance, urban impervious surface area (ISA) in the Hangzhou metropolis illustrates that urban growth before 2000 was mainly due to infilling within the urban landscape; after 2005 growth was due to northward expansion of the urban-rural interfaces (e.g., Li et al., 2016). The satellite images also illustrate that in the Shanghai metropolis, the urban area expanded along a north-south axis from 1979 to 2000, but after 2000 this growth changed to spread from both the existing urban area and along transport routes in all directions (e.g., Yin et al., 2011). In western China, taking Chengdu, Xi'an, Kunming, and Urumqi as cases, each city more than doubled in size from 1988 to 2006, and nearly one-third of new urban land is outside the core in small towns (e.g., Schneider et al., 2015). Such a multinucleated or polycentric urban form is consistent with trends reported for coastal cities in eastern China. However, once we focus on individual cities, we could also find large variability among the spatial patterns of urban expansion, even for the cities in the same geographical region. For example, Wu et al. (2015) reported that Beijing, Tianjin and Shijiazhuang presented a mononuclear concentric polygon pattern, a double-nucleated polygon-line pattern, and a sectorial point pattern, respectively, resulting primarily from their respective topographic constraints as well as urban planning and policy. Michishita et al. (2012) found that two mechanisms of urbanization, new land development and redevelopment of built-up areas, existed in the urban expansion of four cities around Poyang Lake, China.

These individual, city-based studies provide valuable information for urban planning and solving urbanization-related environmental issues. Xuzhou, which lies on the east end of the Eurasian Continental Bridge and is an important transportation hub of China, experienced rapid urban expansion in the last two decades. Ground measurements show the built-up area increased from $64.7 \mathrm{~km}^{2}$ in 1998 to $239.0 \mathrm{~km}^{2}$ in 2010, with the most rapid increase occurring after 2006 (e.g., Zhu et al., 2016). However, using the remote sensing dataset, Wen et al. (2016) classified Xuzhou into a model in which the largest expansion occurred in approximately 2004. Thus, some conflicts likely exist among these existing research results. The conflicting knowledge is not good for resolving urbanization-related issues.

Therefore, this research attempts to improve our understanding of the urban expansion of Xuzhou and, in particular, its spatial pattern and temporal evolution. We will use remote sensing images as the primary data sources. The state-of-the-art retrieval method will be used to retrieve land use/cover categories to reveal the urbanization-induced LUCC. Finally, we will discuss potential factors influencing the LUCC. It is expected the results will provide information for urban planning and be valuable for resolving urbanization-related environmental issues in the future.

\section{Data and Methods}

\subsection{Study Area}

Xuzhou is located in the northwest of Jiangsu province and is near to Shandong Province, Anhui Province and Henan Province (Du et al., 2015). It is located in the range of $117^{\circ} 02^{\prime} \mathrm{E}-117^{\circ} 22^{\prime} \mathrm{E}$ and $34^{\circ} 08^{\prime} \mathrm{N}-34^{\circ} 24^{\prime} \mathrm{N}$, with an area of approximately $819 \mathrm{~km}^{2}$ consisting of Gulou, Quanshan, and Yunlong districts, as well as a part of Jiawang and Tongshan districts (Figure 1). The study area has a 
semi-humid monsoon climate, with an average annual mean temperature of $\sim 14{ }^{\circ} \mathrm{C}$ and annual precipitation of $800-930 \mathrm{~mm}$. The topography is dominated by plains derived from the sediment of the Yellow River and Huai River. This city has been a major hub for trade and transportation. It lies at the east end of the Eurasian Continental Bridge and is an important transportation crossroad of China. Currently, Xuzhou is built as an important node of "The Belt and Road".

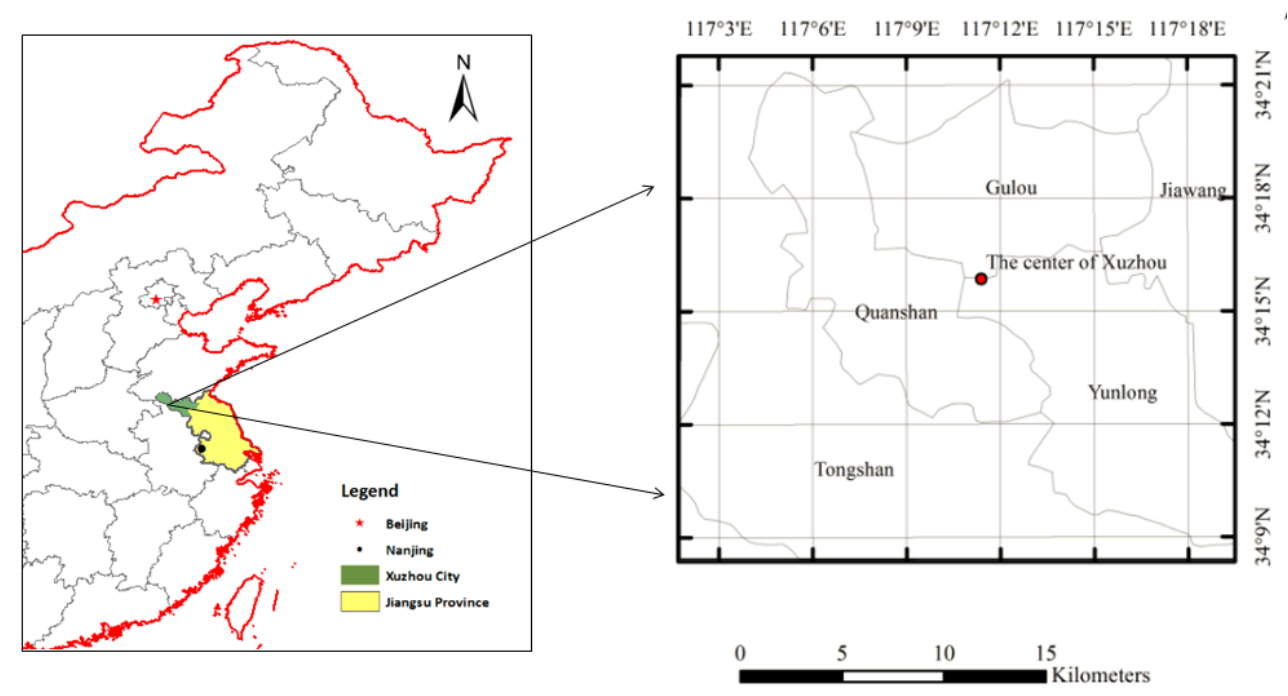

Figure 1. Location of the study area and districts within the Xuzhou metropolis.

\subsection{Data and Methodology}

In this study, multi-temporal remote sensing data were used as data sources for retrieving land use/cover. The Landsat-5 TM images from October 24, 1994 and April 13, 2005 and the Landsat-8 Operational Land Imager (OLI) images from March 21, 2014 were used (available at http://www.gscloud.cn/). All images have a spatial resolution of $30 \mathrm{~m}$. To interpret the spatial pattern of urban expansion, socio-economic data were also applied.

First, we performed the geometric correction on the Landsat-8 OLI image using a topographic map (e.g., Du et al., 2010). Then, "image to image" registration was performed to geometrically correct Landsat-5 TM images with the corrected Landsat-8 OLI image as the reference. The corrections were restrained by the Root Mean Square (RMS) error of less than 1 pixel of 30 by $30 \mathrm{~m}$ (e.g., Ma et al., 2010; Liu et al., 2015).

Second, to retrieve the land use/cover categories, a supervised classification with the maximum likelihood algorithm was used (e.g., Hegazy et al., 2015). In the supervised classification technique, the maximum likelihood algorithm classifies the pixels based on the training sample sites (signatures) provided by the researchers based on their local field knowledge. The training samples then were applied as criteria to classify all the pixels into land use/cover categories (e.g., Peng et al., 2015). Thirty to fifty training sample sites, ranging in size from 342 to 6,210 pixels, were selected and used as areas of interest to classify the images. Based on the researchers' local field experience, there are five categories of land use/cover: building land, arable land, woodland, watershed and unused land. Then, to quantify the accuracy of classification, the confusion matrix approach was applied. An accuracy assessment was performed by computing the overall accuracy, producer's accuracy (PA), consumer's accuracy (CA), and Kappa statistics (Congalton et al., 1999). The overall classification accuracy is calculated by dividing the total number of correctly classified pixels by the total number of reference pixels and is also tested using Kappa statistics (Lillesand et al., 1999). 


\section{Results}

\subsection{Accuracy of Classification}

The classifications of land use categories are shown in Figure 2. The classification accuracy is shown in Tables 1, 2 and 3. The total accuracy of classification was $90.38 \%, 89.81 \%$ and $89.57 \%$, respectively, for 1994, 2005, and 2014. Corresponding to the accuracy, the Kappa coefficients were 0.868, 0.863 and 0.859 , respectively. Generally, the classification accuracies of built-up area and arable land are higher than those of woodland and unused land. The CA and PA of built-up area and arable land were close to, or higher than, 90\%. Following expert guidance, an accuracy of $85 \%$ was considered the threshold value, which indicates the effectiveness of the aforementioned image processing techniques (Anderson et al., 1976). Thereby, the total accuracy of our classification meets the requirements, i.e., the data used for the present urban expansion studies in Xuzhou are generally reliable.

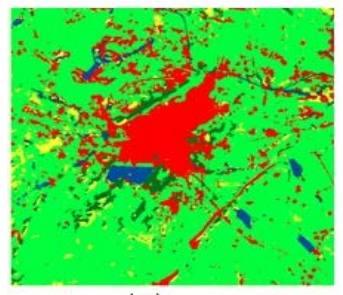

(a)

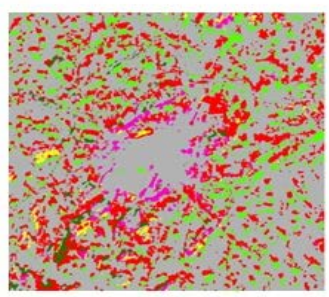

(d)

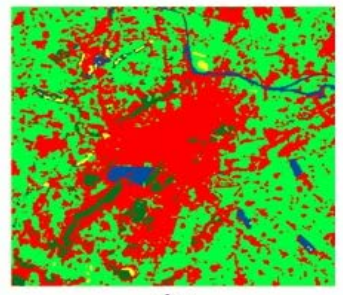

(b)

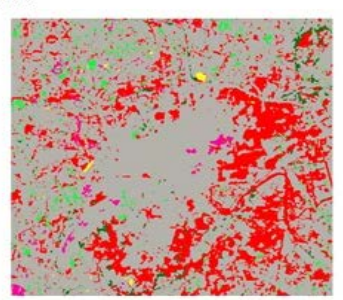

(e)

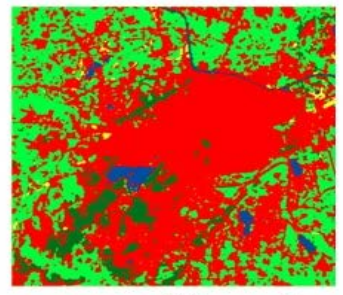

(c)

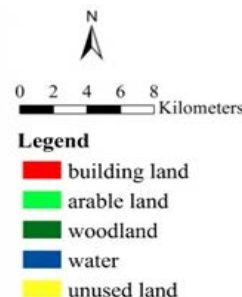

$\bigwedge^{N}$

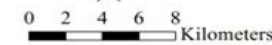

Legend

arable land to building land

arable land to woodland

building land to arable land

woodland to building land

unused land to building land

other types of changes

Figure 2. Land use/cover over Xuzhou retrieved from Landsat images for 1994 (a), 2005 (b), and 2014 (c), and land use/cover changes from 1994 to 2005 (d) and from 2005 to 2014 (e).

Table 1. Accuracy assessment of land use/cover classification for 1994.

\begin{tabular}{clllllll}
\hline Ground Truth & building area & arable land & \multirow{2}{*}{ woodland } & \multirow{2}{*}{ water } & unused land & Total & CA \\
\hline Class Unclassified & 41 & 5 & 0 & 0 & 0 & 46 & 0.891 \\
building area & 1 & 103 & 6 & 2 & 1 & 113 & 0.911 \\
arable land & 0 & 6 & 28 & 0 & 0 & 34 & 0.824 \\
woodland & 0 & 0 & 0 & 32 & 0 & 32 & 1.000 \\
water & 4 & 0 & 0 & 0 & 31 & 35 & 0.886 \\
unused land & 46 & 114 & 34 & 34 & 32 & 260 & \\
Total & 0.891 & 0.904 & 0.824 & 0.941 & 0.969 & & \\
PA & & & & & &
\end{tabular}


Table 2. Accuracy assessment of land use/cover classification for 2005.

\begin{tabular}{|c|c|c|c|c|c|c|c|}
\hline Class Unclassified & $\begin{array}{l}\text { building } \\
\text { area }\end{array}$ & arable land & woodland & water & unused land & Total & $\mathrm{CA}$ \\
\hline building area & 71 & 5 & 0 & 0 & 0 & 76 & 0.934 \\
\hline arable land & 3 & 87 & 3 & 0 & 0 & 93 & 0.936 \\
\hline woodland & 1 & 5 & 28 & 0 & 0 & 34 & 0.824 \\
\hline water & 1 & 1 & 1 & 29 & 0 & 32 & 0.906 \\
\hline unused land & 4 & 3 & 0 & 0 & 23 & 30 & 0.767 \\
\hline Total & 80 & 101 & 32 & 29 & 23 & 265 & \\
\hline $\mathrm{PA}$ & 0.888 & 0.861 & 0.875 & 1.000 & 1.000 & & \\
\hline
\end{tabular}

Table 3. Accuracy assessment of land use/cover classification for 2014.

\begin{tabular}{cccccccc}
\hline Ground Truth & building area & arable land & woodland & water & unused land & Total & CA \\
Class Unclassified & 93 & 10 & 0 & 0 & 0 & 103 & 0.903 \\
building area & 5 & 67 & 1 & 0 & 0 & 73 & 0.918 \\
arable land & 2 & 4 & 38 & 0 & 0 & 44 & 0.864 \\
woodland & 0 & 0 & 0 & 31 & 0 & 31 & 1.000 \\
water & 4 & 3 & 0 & 0 & 20 & 27 & 0.741 \\
unused land & 104 & 84 & 39 & 31 & 20 & 278 & \\
Total & 0.894 & 0.798 & 0.974 & 1.000 & 1.000 & & \\
PA & & & & & & & \\
\hline
\end{tabular}

\subsection{Quantity of Land Use/Cover Changes}

As shown in Figure 2, within the study area, arable land and built-up area were the dominant land use/cover categories. Both arable land and built-up area account for more than $85 \%$ of the study area. From 1994 to 2014, the urban expansion and cropland reduction were distinctive. In 1994, the built-up area occupied $\sim 135.48 \mathrm{~km}^{2}$, accounting for $\sim 16.5 \%$ of the study area (same hereafter); and the arable land surrounding the urban area occupied $\sim 588.91 \mathrm{~km}^{2}$, accounting for $\sim 71.8 \%$. In 2005 , the built-up area expanded to $\sim 323.28 \mathrm{~km}^{2}$, accounting for $\sim 39.4 \%$, which is more than double of that in 1994 , and arable land decreased to $\sim 430.84 \mathrm{~km}^{2}$, accounting for $\sim 52.6 \%$. From 1994 to 2005, approximately 153.18 $\mathrm{km}^{2}$ of arable land was converted into urban area. In 2014 , the built-up area increased to $\sim 456.33 \mathrm{~km}^{2}$, accounting for $\sim 55.7 \%$, which is more than triple of that in 1994; arable land decreased to $\sim 274.21 \mathrm{~km}^{2}$ during this period, accounting for $\sim 33.5 \%$. From 2005 to 2014 , approximately $144.86 \mathrm{~km}^{2}$ of arable land was converted into built-up area. Between 1994 and 2014, net conversions from arable land to built-up area reached as high as $298.04 \mathrm{~km}^{2}$, which accounts for $50.6 \%$ of the arable land area and is more than twice the built-up area in 1994.

Along with the distinctive conversion from arable land to urban area, the conversions among the other types of land use/cover also occurred. For instance, the watershed decreased from $\sim 21.77 \mathrm{~km}^{2}$ in 1994 to $\sim 18.95 \mathrm{~km}^{2}$ in 2005 and to $\sim 15.69 \mathrm{~km}^{2}$ in 2014 . There are also changes in woodland and unused land. However, these changes were very limited and, therefore, would contribute little to urban expansion.

\subsection{The Orientation of Urban Expansion}

The orientation of urban expansion is shown in Figure 3. As we can see, urban expansion occurred around the downtown area, whereas urban expansion was spatially uneven. From 1994 to 2005, the urban area mainly extended to the southwest, comprising approximately $45.54 \mathrm{~km}^{2}$ and accounting for approximately $25 \%$ of the total newly developed urban areas. Next, the new developed urban area occurred in the south, comprising approximately $29.23 \mathrm{~km}^{2}$ and accounting for approximately $17 \%$ of the land. This large, new urban development arose along with the construction of the Guanyin Airport in 
the southwest and the South City Development Zone. The area with the least newly developed urban area (accounting for only approximately $3 \%$ ) was in the north.

From 2005 to 2014, the urbanized area mainly extended to the east and southeast, with approximately $25 \%$ of the total newly developed urban area in the east and southeast. In the following period, approximately $16 \%$ and $13 \%$ of the newly developed urban land was in the northeast and south, respectively. In this period, urban expansion in the southwest likely ceased and there were no newly developed urban areas.

(a)

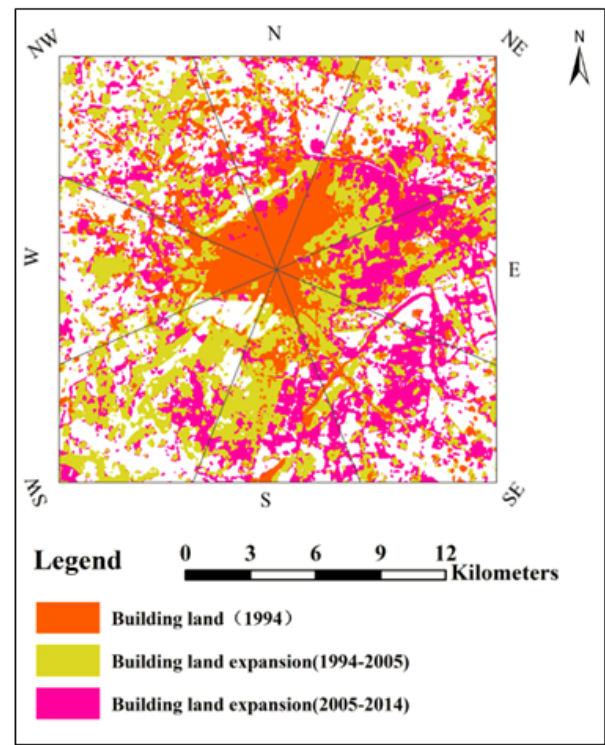

(b)

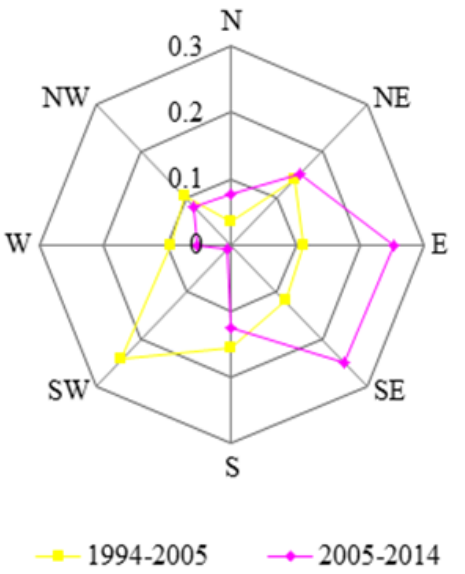

Figure 3. (a) Spatial pattern of urban expansion over Xuzhou from 1994 to 2014 and (b) the fraction of newly developed built-up area in each direction of the total newly developed built-up area for each period.

\subsection{Socio-Economic Development along with Urban Development}

To understand the potential relationship between urban expansion and economic growth, we analyzed the changes in social and economic factors along with the urban expansion from 1994 to 2014. In this study, we considered the Gross Domestic Product (GDP), Non-agricultural population fraction, and Passenger capacity. Non-agricultural population fraction indicates the laborers contributing to secondary and tertiary industries and is thereby closely related with economic growth and urbanization. The passenger capacity can serve as an effective proxy for economic activity, as Xuzhou is an important transportation hub of China.

As shown in Table 4, along with the urban expansion from 1994 to 2014, the total economy increased and economic activity intensified. The GDP increased by approximately $280.7 \%$ and $309.5 \%$ during 1994 to 2005 and 2005 to 2014, respectively. The non-agricultural population and passenger capacity also increased substantially. However, the urban expansion does not match with economic development. In 1994, the GDP and passenger capacity per square kilometer were approximately 2.3 Billon $/ \mathrm{km}^{2}$ and 0.28 Million $/ \mathrm{km}^{2}$, respectively. They increased to 3.7 Billon $/ \mathrm{km}^{2}$ and 0.22 Million $/ \mathrm{km}^{2}$ in 2005 and to 10.9 Billon $/ \mathrm{km}^{2}$ and 0.33 Million $/ \mathrm{km}^{2}$ in 2014. The non-agricultural population density was 12,441 persons $/ \mathrm{km}^{2}$ in $1994,9,775$ persons $/ \mathrm{km}^{2}$ in 2005 , and 16,150 persons $/ \mathrm{km}^{2}$ in 2014 . These figures suggest the urban expansion in the first ten-year period was larger than that in the second ten-year period; however, the economic development was likely faster in the second ten-year period than that in the first ten-year period. This finding suggests that the urban expansion of Xuzhou was likely not driven by the demands of economic development but that the urban expansion provided good conditions for economic development. 
Table 4. Urban expansion and social and economic factors from 1994 to 2014.

\begin{tabular}{ccccc}
\hline Year & $\begin{array}{c}\text { Construction land } \\
\text { area }\left(\mathbf{k m}^{\mathbf{2}}\right)\end{array}$ & $\begin{array}{c}\text { GDP (Billion } \\
\text { yuan) }\end{array}$ & $\begin{array}{c}\text { Non-agricultural population } \\
\text { fraction (\%) }\end{array}$ & $\begin{array}{c}\text { Passenger capacity } \\
\text { (Million) }\end{array}$ \\
\hline 1994 & 135.48 & 318.4 & 19.81 & 38.11 \\
2005 & 323.28 & 1212.15 & 34.15 & 72.02 \\
2014 & 456.33 & 4963.91 & 72.04 & 150.63 \\
\hline
\end{tabular}

\section{Conclusion and Discussion}

These findings demonstrate that Xuzhou experienced large urban expansion within the study area from $135.48 \mathrm{~km}^{2}$ in 1994 to $456.33 \mathrm{~km}^{2}$ in 2014 . The urban expansion came mostly at the cost of a decrease in arable land. More than $90 \%$ of the newly developed urban area was converted from arable land. The urban area expanded mainly to the southwest and south in the first ten-year period (1994-2005), then the urban area expanded mainly to the east and southeast in the second ten-year period (2005-2014). Moreover, the urban expansion appears to have preceded economic growth. It indicates that urban expansion provided good conditions for economic growth rather than being driven by economic growth.

This study depicted the urban expansion of Xuzhou from 1994 to 2014 using high-resolution Landsat images. The results demonstrate that there was faster urban expansion in the first ten-year period than the second ten-year period. The result is slightly different from the previous results that the most rapid increase occurred after 2006 (Zhu et al., 2016). More importantly, this study shows that urban expansion likely occurred ahead of economic development. These results indicate that the urban expansion of Xuzhou may have been mainly driven by policy, rather than by the land demands of economic development, in the first ten-year period.

Finally, it is noted that our results only depict coarse development processes of urbanization as we only used three time slices of Landsat images. Therefore, in the future, many more remote sensing images would be needed to retrieve inter-annual dynamics of the urbanized area. Then, based on the detailed dynamics of urban development, we would improve our present findings to show the relationship between urban expansion and economic growth. Additionally, to address urbanenvironmental issues, the temporal coherence between urban development and environment issues would be worthy of study.

Acknowledgements. This research is supported by the National Natural Science Foundation of China (41471171; 91325302), Youth Innovation Promotion Association CAS (2015038) and Outstanding Young Scholars from IGSNRR (2015RC101).

\section{References}

1. Bai, Xuemei, J. Chen, and P. Shi. "Landscape Urbanization and Economic Growth in China: Positive Feedbacks and Sustainability Dilemmas," Environmental Science $\&$ Technology, 46(1), p.132-139, 2012.

2. Liu, Zhifeng, et al. "How much of the world's land has been urbanized, really? A hierarchical framework for avoiding confusion," Landscape Ecology, 29(5), p.763-771, 2014.

3. Deng, Xiangzheng, et al. "Impact of urbanization on cultivated land changes in China," Land Use Policy, 45(45), p.1-7, 2015.

4. Ministry of Housing and Urban-Rural Development PRC (2011) China Urban Construction Statisitcal Yearbook 2010. Beijing: China Planning Press.

5. Liu, Tao, H. Liu, and Y. Qi. "Construction land expansion and cultivated land protection in urbanizing China: Insights from national land surveys, 1996-2006," Habitat International, 46, p.13-22, 2015.

6. Zhang, Xing Quan. "The trends, promises and challenges of urbanisation in the world," Habitat International, 54, p.241-252, 2016.

7. Xiao, Jieying, et al. "Evaluating urban expansion and land use change in Shijiazhuang, China, by using GIS and remote sensing," Landscape ES Urban Planning, 75.1-2, p.69-80, 2006.

8. Du, Peijun, et al. "Monitoring urban land cover and vegetation change by multi-temporal remote sensing 
information," Mining Science 83 Technology, 20(6), p.922-932, 2010.

9. Sertel, Elif, et al. "Spatio-temporal analysis of urbanization related land use/cover dynamics using satellite imagery: Case study Antalya, Turkey," Asian Conference on Remote Sensing. 2012.

10. Min, Xu, et al. "How Did Urban Land Expand in China between 1992 and 2015? A Multi-Scale Landscape Analysis," Plos One11.5(2016):e0154839.

11. Liu, Jiyuan, et al. "Study on spatial pattern of land-use change in china during 1995-2000," Science in China, 46(4), p.373-384, 2003.

12. Liu, Jiyuan, et al. "Spatial patterns and driving forces of land use change in china during the early 21st century," Journal of Geographical Sciences, 20(4), p.483-494, 2010.

13. Jiyuan, et al. "Spatiotemporal characteristics, patterns, and causes of land-use changes in china since the late 1980s," Journal of Geographical Sciences, 24(2), p.195-210, 2014.

14. Kuang, Wenhui, et al. "The rapid and massive urban and industrial land expansions in china between 1990 and 2010: a CLUD-based analysis of their trajectories, patterns, and drivers," Landscape \& Urban Planning, 145, p.21-33, 2016.

15. WANG, et al. "China's urban expansion from 1990 to 2010 determined with satellite remote sensing," Chinese Science Bulletin, 57(22), p.2802-2812, 2012.

16. Li, Longwei, D. Lu, and W. Kuang. "Examining urban impervious surface distribution and its dynamic change in Hangzhou metropolis," Remote Sensing, 8(3), 2016.

17. Yin, J., et al. "Monitoring urban expansion and land use/land cover changes of shanghai metropolitan area during the transitional economy (1979-2009) in china," Environmental Monitoring \& Assessment, 17r7(1-4), p.609-621, 2011.

18. Schneider, Annemarie, C. Chang, and K. Paulsen. "The changing spatial form of cities in western china," Landscape \& Urban Planning, 135, p.40-61, 2015.

19. Wu, Wenjia, et al. "A comparative study of urban expansion in Beijing, Tianjin and Shijiazhuang over the past three decades," Landscape \&3 Urban Planning, 134, p.93-106, 2015.

20. Michishita, Ryo, Z. Jiang, and B. Xu. "Monitoring two decades of urbanization in the poyang lake area, china through spectral unmixing," Remote Sensing of Environment, 117(1), p.3-18, 2012.

21. Qingke, et al. "Extraction of basic trends of urban expansion in china over past 40 years from satellite images," Chinese Geographical Science, 26(2), p.129-142, 2016.

22. Du, Peijun. "Monitoring urban impervious surface area change using china-brazil earth resources satellites and hj-1 remote sensing images," Journal of Applied Remote Sensing, 9(1), 2015.

23. Ma, Yueliang, and R. Xu. "Remote sensing monitoring and driving force analysis of urban expansion in Guangzhou city, China," Habitat International, 34(34), p.228-235, 2010.

24. Liu, Ting, and X. Yang. "Monitoring land changes in an urban area using satellite imagery, GIS and landscape metrics," Applied Geography, 56, p.42-54, 2015.

25. Hegazy, Ibrahim Rizk, and M. R. Kaloop. "Monitoring urban growth and land use change detection with GIS and remote sensing techniques in Daqahlia governorate Egypt," International Journal of Sustainable Built Environment, 4(1), p.117-124, 2015.

26. Peng, Wenfu, et al. "Studies on the temporal and spatial variations of urban expansion in Chengdu, western China, from 1978 to 2010," Sustainable Cities \&S Society, 17, p.141-150, 2015.

27. Congalton, R.G., Green, K. "Assessing the Accuracy of Remotely Sensed Data: Principles and Practices," Lewis Publishers, New York, 1999.

28. Lillesand, T. M., \& Kiefer, R. W. (1999). Remote sensing and image interpretation. New York: Wiley.

29. Tan, Minghong, et al. "Urban land expansion and arable land loss in China - a case study of Beijing-TianjinHebei region," Land Use Policy, 22(3), p.187-196, 2005.

30. Zhu, Jishuai, et al. "Human Settlement Analysis Based on Multi-temporal Remote Sensing Data: A Case Study of Xuzhou City, China," Chinese Geographical Science, 26(3), p.389-400, 2016. 